\title{
Intestinal duplication isolated from the digestive tract: an entity to be considered
}

\author{
C. Grande Moreillo, J. Margarit Mallol, S. Fuentes Carretero \\ Pediatric Surgery Department. Mútua de Terrassa University Hospital. Terrassa, Barcelona (Spain).
}

\begin{abstract}
Objectives. To review intestinal duplications isolated from the digestive tract.

Materials and methods. Description of the 27 isolated intestinal duplication cases published; presentation of a new case.

Results. Intestinal duplication isolated from the digestive tract represents an extremely rare malformation. This type of duplication is not in close contact with any segment of the intestinal tract, and it has its own vascular pedicle. Preoperative diagnosis rates are lower than those found in classic duplications. In addition to the potential complications, malformation torsion is also to be considered.

Conclusions. This infrequent variant is to be considered at differential diagnosis. Potential torsion should also be taken into account in order to decide when an asymptomatic patient should undergo surgery.
\end{abstract}

KEY WoRDS: Intestinal duplication; Isolated and non-communicating.

\section{DUPLICACIÓN INTESTINAL AISLADA RESPECTO AL TRACTO DIGESTIVO: UNA ENTIDAD A TENER EN CUENTA}

\section{RESUMEN}

Objetivos. Revisión de las duplicaciones intestinales aisladas, sin conexión con el tracto digestivo.

Material y métodos. Se recopilan los 27 casos de duplicación intestinal aislada publicados hasta el momento y se presenta un nuevo caso.

Resultados. Las duplicaciones intestinales aisladas sin conexión con el tracto digestivo representan una variante de la malformación extremadamente rara. Este tipo de duplicaciones no están en contacto íntimo con ningún segmento del tracto intestinal y cuelgan de un pedículo vascular propio. Tienen menos tasa de diagnóstico prequirúrgico que las duplicaciones clásicas y a las posibles complicaciones hay que añadir la torsión de la malformación.

DOI: $10.54847 /$ cp.2022.01.17

Corresponding author: Dra. Carme Grande Moreillo.

E-mail address: carme.grande@gmail.com

Date of submission: November 2020 Date of acceptance: October 2021
Conclusiones. Es interesante conocer esta variante infrecuente para considerarla en el diagnóstico diferencial. La posibilidad añadida de torsión debe tenerse en cuenta para decidir el momento de la cirugía en el paciente asintomático.

Palabras Clave: Duplicación intestinal; Aislada y no comunicada.

\section{INTRODUCTION}

Intestinal tract duplication is a congenital malformation with the following characteristics: a well-developed smooth muscle layer, a mucosal lining representing any kind of gastrointestinal mucosa, and a close anatomical association with any given portion of the gastrointestinal tract. It can be located anywhere, from the oropharynx to the anus ${ }^{(1)}$.

Intestinal duplication isolated from the digestive tract represents an extremely rare malformation, with 27 cases published up until now ${ }^{(2-26)}$.

\section{MATERIALS AND METHODS}

Description of the 27 isolated intestinal duplication cases published (Table I), and presentation of a new case.

\section{RESULTS}

\section{Clinical case}

Female newborn prenatally diagnosed with double bubble. Simple abdominal X-ray 2 and 24 hours following birth showed air leakage through the small bowel.

Ultrasonography at 36 hours of life demonstrated a $5.5 \times 1.9 \mathrm{~cm}$ cystic mass at the level of the left epigastrium consistent with a duplication cyst. The patient had no symptoms.

Control ultrasonography at one month of life showed the cystic mass had not changed in size, with an abnor- 


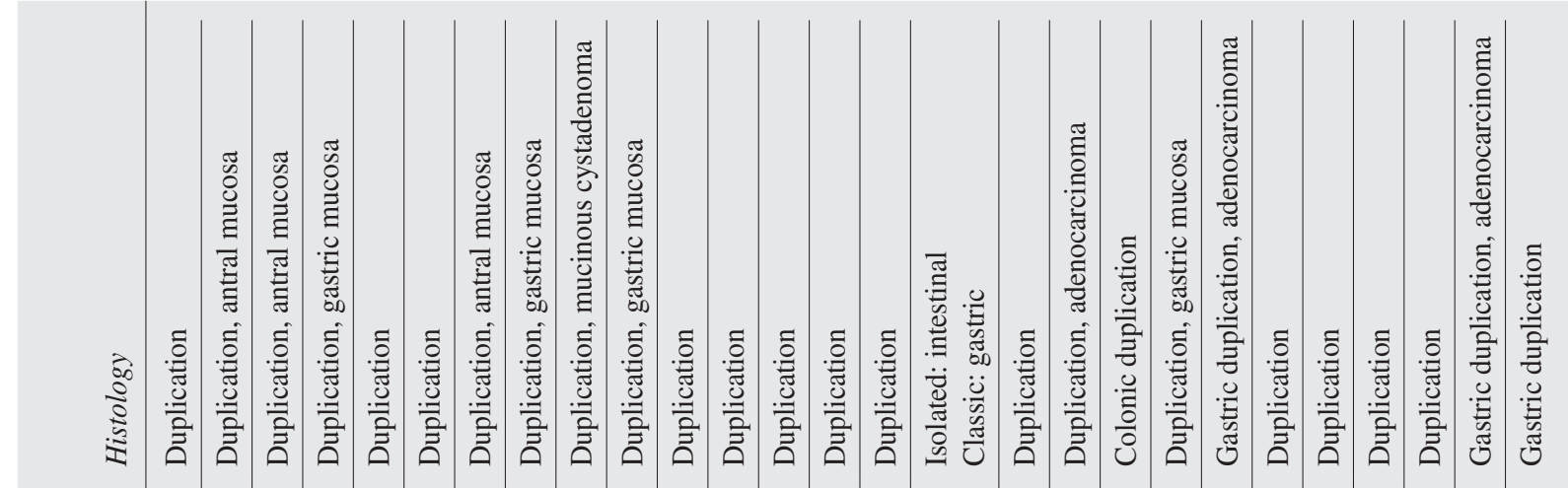

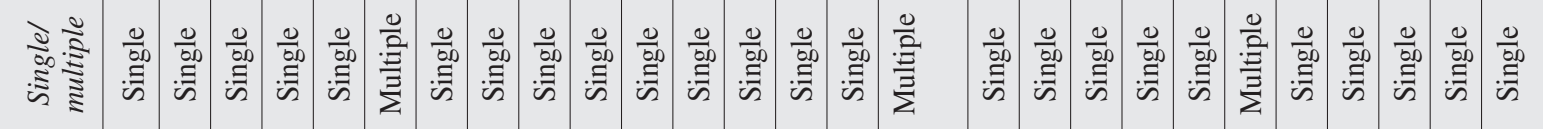

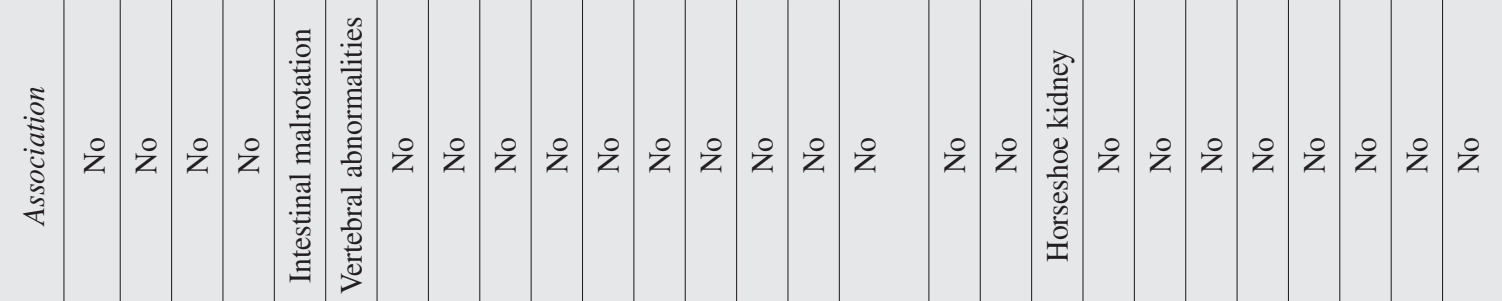

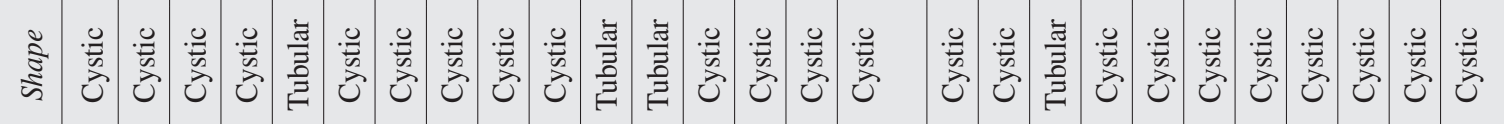

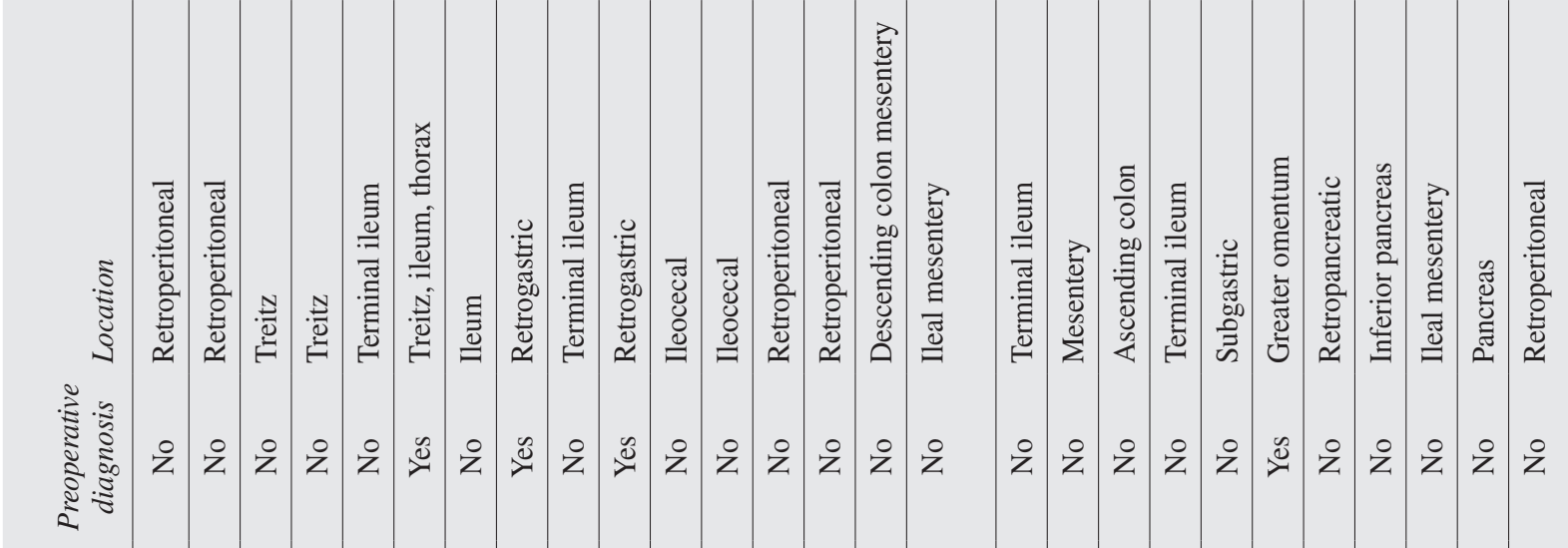

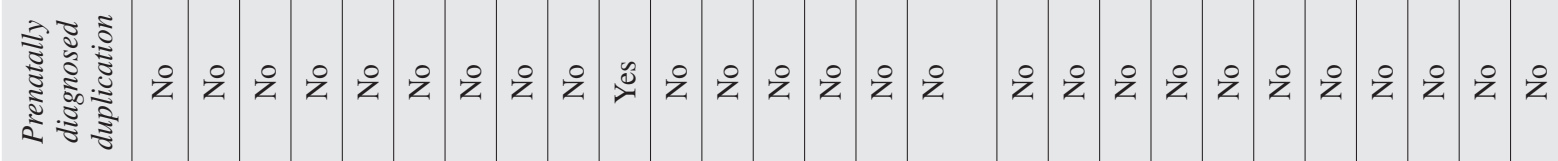

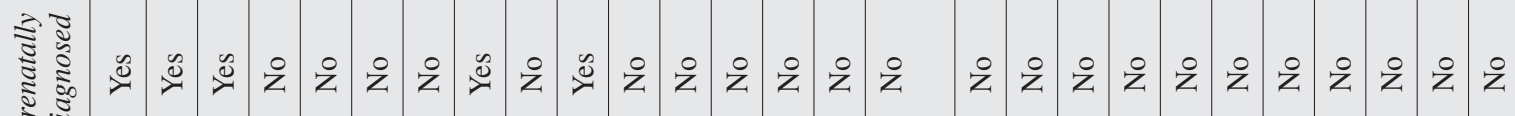
ะี้ำ

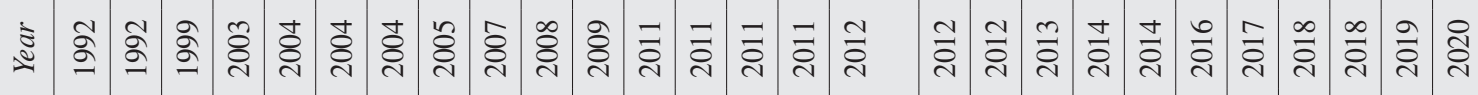

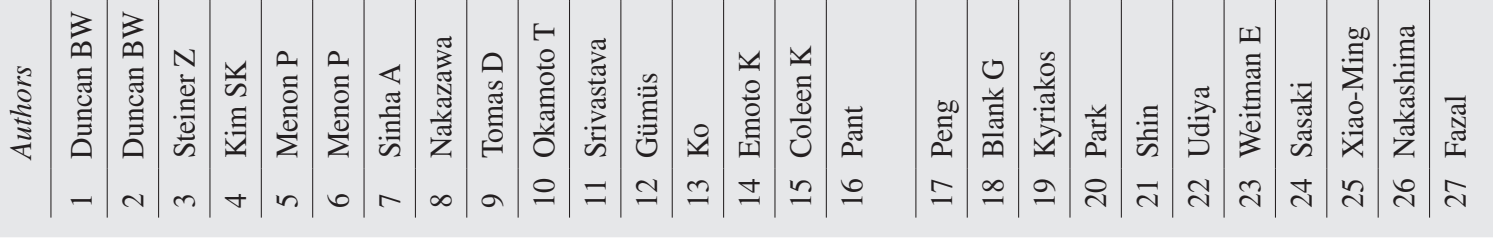




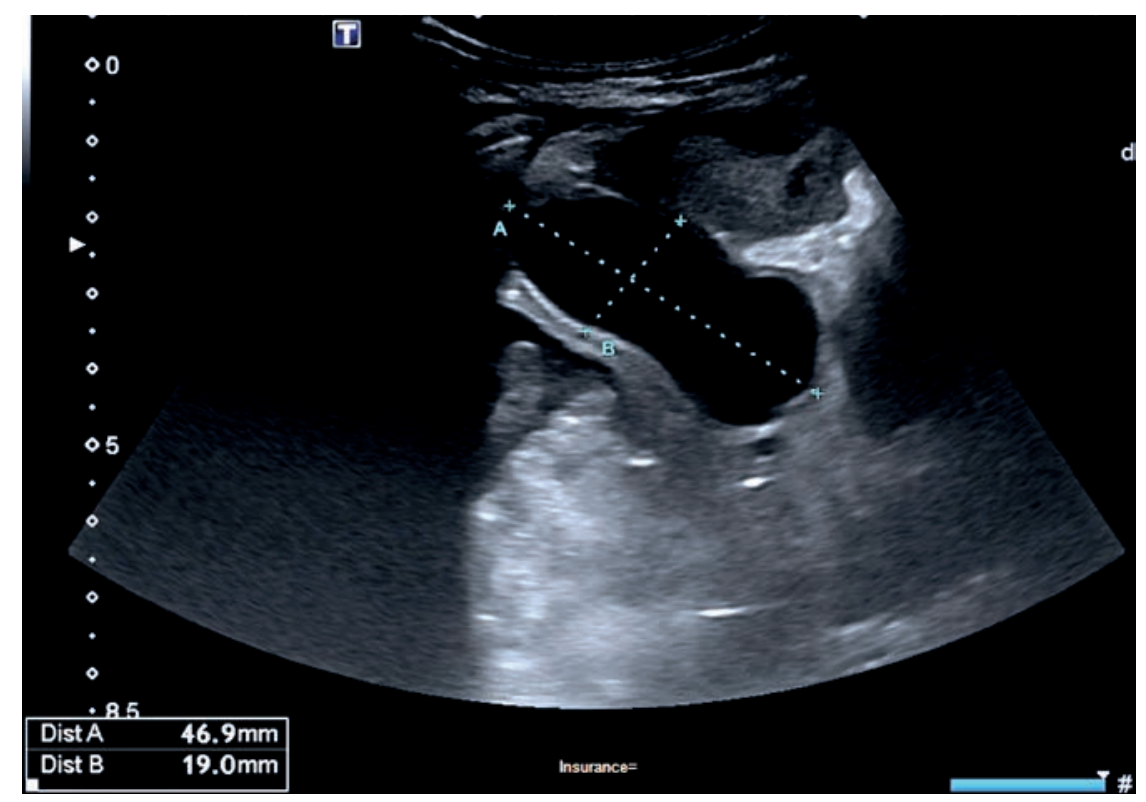

Figure 1. Abdominal ultrasonography at 1 month of life.

mal $5 \mathrm{~mm}$ communication with an intestinal structure (Fig. 1).

The family did not attend the following controls until the patient had turned 1 year old, when a new ultrasonography was carried out. It showed a $10 \times 4 \mathrm{~cm}$ cystic image at the left hypochondrium, anterior to the kidney. Since it had doubled in size, surgery was indicated.

An exploratory laparoscopy was carried out. It showed a large cyst at the left upper quadrant. The lesion was dissected until the angle of Treitz. No association with any portion of the gastrointestinal tract was found. Following conversion to open surgery, dissection was pursued. The cyst extended to the mesenteric root, where its vascular pedicle came from. No association with any intestinal loop or other organs was noted (Fig. 2).

Pathological examination demonstrated the presence of a cystic formation consisting of a smooth muscle wall - made up of two layers, with nerve plexuses between them -, along with another layer of smooth muscle tissue with a hypertrophic muscularis mucosae morphology at the subepithelial region. On the surface, gastric antral mucosa was identified, with a mild lymphocytic infiltrate in the lamina propria. No intestinal mucosa was observed. There were no signs of dysplasia or malignity.

Postoperative progression was favorable. The patient tolerated food reintroduction after 24 hours, and she was discharged three days following surgery.

\section{LITERATURE REVIEW}

A literature review was carried out. It showed 27 similar cases published up until now -14 pediatric cases and 13 adult $\operatorname{cases}^{(2-26)}$ (Table I).

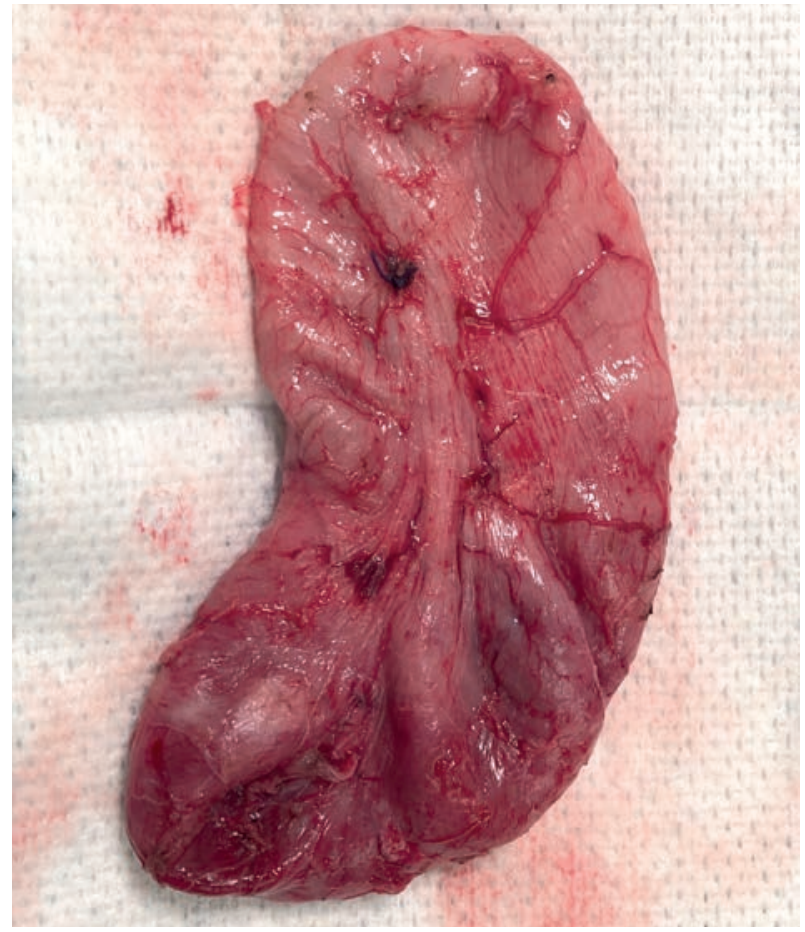

Figure 2. Surgical specimen.

Of the 14 pediatric cases, 5 had been prenatally diagnosed with abdominal cystic mass ${ }^{(2,3,7,9)}$, one of which was managed as an intestinal duplication ${ }^{(9)}$.

In two adult patients, diagnosis was achieved incidentally ${ }^{(8,17)}$. In the other patients, both adult and pediatric, diagnosis was established based on clinical signs (74\%), but duplication was suspected before surgery in three cases only ${ }^{(5,7,21)}$. None of the patients was diagnosed with intes- 


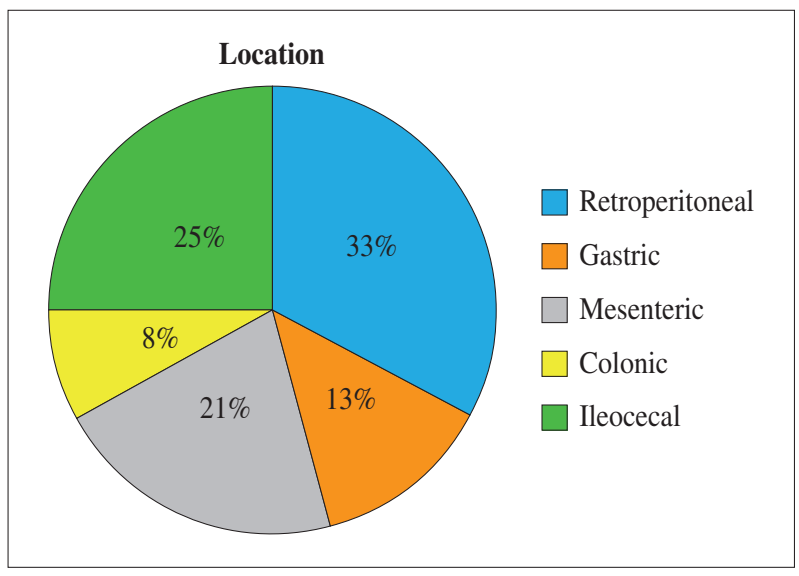

Figure 3. Location of duplications in the series.

tinal duplication isolated from the digestive tract. In four patients, an abdominal mass was found - it was palpated at birth in two ${ }^{(5,6)}$, and at adulthood in the others ${ }^{(4,14)}$. A 7-month-old boy had clinical signs of abdominal distension ${ }^{(5)}$. The other cases started with abdominal pain.

Emergency surgery was carried out in 3 out of the 27 patients. In a 4-day old boy with breastfeeding refusal and lethargy, an abdominal mass and severe anemia were found, with cyst bleeding during surgery( ${ }^{(6)}$. In the other two - an 18-month old boy and a 20-year old adult -, intestinal volvulus was suspected, and surgery demonstrated duplication torsion with necrosis ${ }^{(15,24)}$.

Three patients had multiple duplications ${ }^{(5,15,21)} .23$ were cystic and 4 were tubular. In three cases, it was associated with other malformations - intestinal malrotation ${ }^{(5)}$, vertebral and thoracic abnormalities ${ }^{(5)}$, and horseshoe kidney ${ }^{(18)}$, respectively.

Location is featured in figure 3. Of the three multiple duplications, one occurred at the ileal mesentery, one was located at the transverse mesocolon and the omentum, and the other one had various duplication cysts in the region of the angle of Treitz, the ileum, and the thorax.

The origin of the vascular pedicle varied. Vascularization came from the retroperitoneal area in eight cases, from the mesentery in six cases, from the angle of Treitz's area in two cases, and from the gastroepiploic arcade in one case. It was not specified in ten cases.

The final result of the histological analysis showed adenocarcinoma within the duplication in 3 out of the 27 cases, and mucinous cystadenoma with high grade dysplasia in one case.

\section{DISCUSSION}

Intestinal duplication is a rare malformation. It may be located at any segment of the digestive tract, from the oropharynx to the anus. It can be single or multiple, cystic or tubular. Symptoms vary according to size, location, and mucosal type inside ${ }^{(1)}$.

Most duplications share common characteristics, including the presence of a well-developed smooth muscle layer, a mucosal lining representing any kind of gastrointestinal mucosa, and a close anatomical association with any given portion of the gastrointestinal tract, with which they share vascularization ${ }^{(1)}$. However, this last feature was not present in the duplications analyzed in this review.

The etiology of intestinal duplication remains unclear. Various hypotheses have been proposed, but the diverticulization theory - a persistent diverticulum at the intestinal mesenteric border, when it should be transitory - is the only one that could explain isolated intestinal duplication. Steiner suggested it could be caused by a torsion-like event or a vascular lesion at the proximal portion of the diverticulum ${ }^{(3)}$.

Prenatal diagnosis of intestinal duplication is increasing thanks to the improvement of routine screening in the second trimester. Nevertheless, prenatal diagnosis is not an easy task, with only 20-30\% of cases being diagnosed before birth ${ }^{(27)}$. In addition, while detecting a cystic mass can be relatively simple, identifying its origin is much less so. Relationship with adjacent structures and time of occurrence, as well as cyst shape and size, can help achieve an accurate diagnosis. Various studies have analyzed the correspondence of prenatal ultrasound diagnosis with postnatal confirmed diagnosis, and have found a positive predictive value of approximately $70 \%{ }^{(28,29)}$. According to Catania ${ }^{(30)}$, intestinal duplication cyst is the most poorly diagnosed intra-abdominal cystic mass.

Including the review and the new case, the cystic mass was prenatally diagnosed in 6 out of the $14(42.85 \%)$ pediatric cases studied, but only one (7.14\%) was diagnosed with intestinal duplication. This is a much lower proportion than that found in classic duplication, where prenatal diagnosis is achieved in 20-30\% of cases.

The patient prenatally diagnosed with intestinal duplication underwent fetal magnetic nuclear resonance following ultrasound detection of an abdominal cystic mass. Various groups have reported the use of MNR as a second-line test in the diagnosis of malformations or fetal abnormalities. In their study, Hugele et al. ${ }^{(31)}$ compared ultrasound diagnoses with fetal resonance and postnatal diagnosis, and found that fetal MNR plays a significant complementary role. In $26.5 \%$ of cases, it provides with diagnostic information regarding intra-abdominal cysts especially supramesenteric lesions -, as it occurred with Okamoto's case ${ }^{(9)}$.

Abdominal ultrasonography also plays an important role in postnatal diagnosis. Duplication cysts are usually round or tubular, with a double wall( ${ }^{(32)}$. However, even though this "gut signature" is characteristic, it is not pathognomonic, since it can be found as an artifact in other pathologies. This is what occurred in Park's case ${ }^{(19)}$, 
where a cystic mass with a layered appearance was found, but it was managed as an ovarian torsion. Furthermore, complicated duplications may also lose this double layer as a result of infection, erosion, etc. ${ }^{(35)}$.

With the improvement of ultrasonographers' technical skills, and in expert hands, new ultrasound signs for diagnosing duplication have been described ${ }^{(27)}$. Up to five layers can be seen: the echogenic, most internal layer corresponding with the mucosa; a hypoechoic layer - the muscularis mucosae; the hyperechoic submucosal layer; the hypoechoic muscularis propria layer; and the most external layer - the hyperechogenic serosa. The separation of the muscularis mucosae between the cyst and the adjacent loop can also be visualized, revealing a typical Y-shaped image. However, this sign cannot be observed in isolated duplications, since there is no connection with any loop whatsoever. Finally, owing to the fact this is a dynamic exploration, peristalsis can be detected within the duplication, with concentric contractions of the cyst wall.

However, in spite of these improvements, only four cases $(14.8 \%)$ in this review were diagnosed with intestinal duplication before surgery: one prenatally through MNR, two with prenatal diagnosis of intra-abdominal cystic mass - with the study being completed neonatally through ultrasonography or CT-scan -, and one at 10 weeks of life through ultrasonography and CT-scan.

Isolated duplication was not suspected in any of these cases.

In pediatric patients, CT-scan is not routinely carried out due to radiation, and MNR is not routinely performed as it requires sedation. However, they both play an important role in duplications at places where ultrasonography has limitations ${ }^{(35)}$.

Clinical signs of intestinal duplication are equally diverse as location. They can be either acute and life-threatening, or incidentally diagnosed. They can bring about symptoms as a result of compression of the neighboring structures, induce a volvulus, become perforated due to cyst congestion or mucosal ulceration in case of gastric or pancreatic heterotopia, and cause bleeding. Isolated duplications follow the same pattern in terms of symptoms, as it can be seen in this series: three required emergency surgery, two were incidentally diagnosed, and the others had clinical signs of abdominal pain, most times associated with vomit and abdominal mass at palpation. In the case of isolated duplications, potential torsion of the duplication cyst itself should also be taken into account, as it occurred in Pant and Xiao-Ming's cases ${ }^{(15,24)}$, which required emergency surgery.

Degeneration is also to be considered. In this series, there are three cases of adenocarcinoma ${ }^{(16,17,25)}$ and one case of mucinous cystadenoma with high grade dysplasia ${ }^{(8)}$, which accounts for $14.8 \%$, all of them in adults. In our view, this proportion is large enough to support surgery, even in the absence of symptoms.
Today, there is no consensus as to when duplication should be resected in prenatally diagnosed patients. On the one hand, the possibility of developing a severe pathology such as volvulus, invagination, perforation, or bleeding supports early neonatal surgery. But on the other hand, it could be deferred in some asymptomatic patients, in order to avoid general anesthesia and surgery at such an early age, thus limiting the potential neurocognitive damage induced by general anesthesia at an early stage of neural development ${ }^{(35)}$. Nevertheless, the clinical progression of duplication cysts is unpredictable. Fahy et al. carried out a systematic review of patients prenatally diagnosed with intestinal duplication to analyze the reason for surgery and the age it had been indicated at. They found that $41 \%$ of patients had clinical signs before surgery. None of the parameters analyzed - duplication size, age at diagnosis, location, etc. - was demonstrated to be able to predict which patients could undergo observation prior to surgery, and which patients should undergo early surgery ${ }^{(36)}$. None of the patients in Fahy's review had isolated duplication. Therefore, the possibility of malformation torsion was not even considered.

To sum up, intestinal duplications isolated from the digestive tract are an extremely rare malformation. They are even more difficult to diagnose - both prenatally and postnatally - than classic duplications, most likely as a result of how difficult it is to establish a clear relationship with the neighboring structures. In both cases, progression is uncertain, which means the best time for surgery is also unknown. Early neonatal MNR, without sedation, should be regarded as one of the initial diagnostic tools in patients prenatally diagnosed with intra-abdominal cystic mass, since it provides with further information about the condition.

It is important to understand this subtype of intestinal duplications and to have the possibility of malformation torsion in mind during the decision-making process.

\section{REFERENCES}

1. Lund DP. Alimentary tract duplications. In: Coran AG, Adzick NS, Krummel T, Laberge J-M, Shamberger R, eds. Pediatric Surgery. Philadelphia: Saunders; 2012.

2. Duncan BW, Adzick NS, Eraklis A. Retroperitoneal alimentary tract duplications detected in utero. J Ped Surg. 1992; 27 (9): 1231-3.

3. Steiner Z, Mogilner J. A rare of completely isolated duplication cyst of the alimentary tract. J Ped Surg. 1999; 34(8): 1284-6.

4. Kim SK, Lim HK, Lee SJ, Park CK. Completely isolated enteric duplication cyst: case report. Abdom Imaging. 2003; 28: 12-4.

5. Menon P, Rao KL, Vaiphei K. Isolated enteric duplication cysts. J Ped Surg. 2004; 39(8): e: 5-7.

6. Sinha A, Ojha S, Sarin YK. Completely isolated, noncontiguous duplication cyst. Eur J Pediatr Surg. 2006; 16(2): 127-9.

7. Nakazawa N, Okazaki T, Miyano T. Prenatal detection of isolated gastric duplication cyst. Pediatr Surg Int. 2005; 21(10): 831-4. 
8. Tomas D, Zovak M, Cicek S, Sulentic P, Jukic Z, Kruslin B. Mucinous cystadenoma arising in an isolated ileal duplication cyst. J Gastrointest Cancer. 2007; 38(2-4): 127-30.

9. Okamoto T, Takamizawa S, Yokoi A, Satoh S, Nishijima E. Completely isolated alimentary tract duplication in a neonate. Pediatr Surg Int. 2008; 24: 1145-7.

10. Srivastava P, Gangopadhyay AN, Kumar V, et al.Noncommunicating isolated enteric duplication cyst in childhood. J Ped Surg. 2009; 44(7): e9-E10.

11. Gümüs M, Kapan M, Gümüs H, Onder A, Girgin S. Unusual noncommunicating isolated enteric duplication cyst in adults. Gastroenterol Res Pract. 2011; 2011: 323919.

12. Ko SF, Ng SH, Huang FC, Sung MT, Hsieh CS. Postprandrial abdominal pain owing to isolated enteric duplication cyst in the superior mesenteric artery root: sonographic and magnetic resonance imaging features. J Ped Surg. 2011; 46(4): 772-5.

13. Emoto K, Mukai M, Kawachi S, Kitagawa Y, Sakamoto M. Duplication of the digestive organs in the retroperitoneum: a case report with reference to the importance of a standardized nomenclature and definition. Pathol Int. 2011; 61(7): 430-4.

14. Nichols KC, Pollema T, Moncure M. Laparoscopically excised completely isolated enteric duplication cyst in adult female: a case report. Surg Laparosc Endosc Percutan Tech. 2011; 21(4): e173-5.

15. Pant N, Grover JK, Madan NK, Chadha R, Agarwal K, Choudhury SR. Completely isolated enteric duplication cyst associated with a classic enterogenous duplication cyst. J Indian Assoc Pediatr Surg. 2012; 17(2): 68-70.

16. Peng HL, Su CT, Chang CY, Lau BH, Lee CC. Unusual imaging features of completely isolated enteric duplication in a child. Pediatr Radiol; 2012; 42(9): 1142-4.

17. Blank G, Königsrainer A, Sipos B, Ladurner R. Adenocarcinoma arising in a cystic duplication of the small bowel: case report and review of literature. World J Surg Oncol. 2012; 10: 55.

18. Kyriakos N, Andreas C, Elena S, Charalampos A, Chrisanthos $\mathrm{G}$. Infected completely isolated enteric duplication cyst management with percutaneous drainage and surgical excision after retreat of infection: a case report. Case Rep Surg. 2013; 2013: 1081126.

19. Park JY, Her KH, Kim BS, Maeng YH. A completely isolated intestinal duplication cyst mimicking ovarian cyst torsion in an adult. World J Gastroenterol. 2014; 20(2): 603-6.

20. Shin SY, Cho MY, Ryu H, et al. Adenocarcinoma originating from a completely isolated duplication cyst of the mesentery in an adult. Intes Res. 2014; 12(4): 328-32.

21. Udiya AK, Shetty GS, Chauhan U, Singhal S, Prabhu SM. Multiple isolated enteric duplication cysts in an infant: a diagnostic dilemma. J Clin Diagn Re. 2016; 10(1): TD15-TD16.

22. Weitman E, Al Diffalha S, Centeno B, Hodul P. An isolated intestinal duplication cyst masquerading as a mucinous cystic neoplasm of the pancreas: A case report and review of the literature. Int J Surg Case Rep. 2017; 39: 208-11.

23. Sasaki N, Okamura M, Kanto S, Tatsumi K, Yasuda S, Kawabe A. Laparoscopic excision of a retroperitoneal completely isolated enteric duplication cyst in an adult male: a case report and review of literature. Int J Surg Case Rep. 2018; 46: 1-5.

24. Xiao-Ming A, Jin-Jing L, Li-Chen H, et al. A huge completely isolated duplication cyst complicated by torsion and lined by 3 different mucosal epithelial components in an adult: a case report. Medicine (Baltimore). 2018; 97(44): e13005.

25. Nakashima S, Yamada T, Sato G, et al. A case of completely isolated advanced enteric duplication cyst cancer performed partial pancreatectomy. Int J Surg Case Rep. 2019; 54: 83-6.

26. Fazaf F, Okiro P. Retroperitoneal isolated enteric duplication cyst. JPS Case Reports. 2020; 55: 101408.

27. Sangüesa C, Llorens R, Carazo E, et al. Enteric duplication cysts in children: varied presentations, varied imaging findings. Insights Imaging. 2018; 9(6): 1097-106.

28. Marchitelli G, Stirnemann J, Acanfora MM, Rousseau V, Salomon LJ, Ville Y. Prenatal diagnosis of intra-abdominal cystic lesions by fetal ultrasonography: diagnostic agreement between prenatal and postnatal diagnosis. Prenat Diagn. 2015; 35(9): 848-52.

29. Lewis S, Walker J, McHoney M. Antenatally detected abdominal cyst: does cyst size and nature determine postnatal symptoms and outcome? Early Hum Dev. 2020; 147: 105102.

30. Catania V, Briganti V, Di Giacomo V, et al. Fetal intra-abdominal cysts: accuracy and predictive value of prenatal ultrasound. J Matern Fetal Neonatal Med. 2016; 29(10): 1691-9.

31. Hugele F, Dumont C, Boulot P, Couture A, Prodhomme O. Does prenatal MRI enhance fetal diagnosis of intra-abdominal cysts? Prenat Diagn. 2015; 35(7): 669-74.

32. Di Serafino M, Mercogliano C, Vallone G. Ultrasound evaluation of enteric duplication cyst: the gut signature. J Ultrasound. 2015; 19(2): 131-3.

33. Silva CT, Engel C, Cross SN, et al. Postnatal sonographic spectrum of prenatally detected abdominal and pelvic cysts. AJR Am J Roentgenol. 2014; 203(6): W684-W696.

34. Rasool N, Safdar CA, Ahmad A, Kanwal S. Enteric duplication in children: clinical presentation and outcome. Singapore Med J. 2013; 54(6): 343-6.

35. Lee NK, Kim S, Jeon TY, et al. Complications of congenital and developmental abnormalities of the gastrointestinal tract in adolescents and adults: evaluation with multimodality imaging. Radiographics. 2010; 30(6): 1489-507.

36. Sinner B, Becke K, Engelhard K. General anaesthetics and the developing brain: an overview. Anaesthesia. 2014; 69(9): 1009-22.

37. Fahy AS, Pierro A. A systematic review of prenatally diagnosed intra-abdominal enteric duplication cysts. Eur J Pediatr Surg. 2019; 29(1): 68-74. 